\title{
Providing Exemplars in the Learning Environment: the Case for and against
}

\author{
David Newlyn \\ School of Law, University of Western Sydney, Sydney, New South Wales, Australia \\ *Corresponding Author: d.newlyn@uws.edu.au
}

Copyright (C) 2013 Horizon Research Publishing All rights reserved.

\begin{abstract}
Contemporary education has moved towards the requirement of express articulation of assessment criteria and standards in an attempt to provide legitimacy in the measurement of student performance/achievement. Exemplars are provided examples of best or worst practice in the educational environment, which are designed to assist students to increase their understanding of particular skills, content or knowledge in any given situation and articulate established criteria and standards. This article examines both the case for and the case against their use in any learning environment and includes issues such as students' desire for exemplars and the concern that the use of exemplars can lead to copying or plagiarism.
\end{abstract}

Keywords Exemplars, learning, education

\section{Introduction}

'Tell me and I forget, teach me and I may remember, involve me and I learn.'

This quote, attributed to Benjamin Franklin, provides a somewhat apposite starting point for this paper as the use of exemplars can be viewed as an important tool in the improvement of a student's grasp of key concepts, skills, content and assessment standards and criteria. For as Price, Handley, Miller and O'Donovan, have made explicit, in order for learning to be effective, students must have a genuine connection to the content they are being asked to learn. ${ }^{1}$ It is submitted that this exposure cannot occur via broad concepts or criteria being presented in a vacuum, rather it must occur when students are presented with information in a genuinely engaging contextual format. This may be achieved via the use of exemplars.

\section{Definition of the Term 'Exemplar'}

\footnotetext{
1 Margaret Price, Karen Handley, Jill Miller and Berry O’Donovan, "Feedback: all that effort, but what is the effect?" Assessment and Evaluation in Higher Education, 35 no.3 (2011): 277-289.
}

Exemplar can simply mean a model, ideal or pattern to be copied or imitated or something typical or representative of an example. Given this broad potential meaning, the definition of exemplar in the context of this paper, therefore, needs to be made as clear as possible.

Writing extensively in the field of exemplars, Sadler proffers that exemplars are "key examples of products or processes chosen so as to be typical of designated levels of quality or competence." ${ }^{2}$ Handley, Price and Miller suggest that exemplars are examples of skills and content that need to be provided in future assessment items as models from previous students work. ${ }^{3}$ Whilst Scoles, Huxham and McArthur define exemplars as simply as "examples of real students' work, generally of different qualities." 4

Exemplars and model answers are similar. Exemplars are usually samples of past work completed by former students who have undertaken work of a specified quality. Model answers are usually specific examples of a 'perfect' answer as constructed by the educator. As such, model answers may not be realistic in their portrayal of what students at that particular level of achievement are capable of and can represent unrealistic and potentially unachievable expectations for current students.

Exemplars may indicate a grade range, as it typical at most institutions, such as fail, pass, credit, distinction and high distinction, and they may be annotated so as to indicate how the exemplar satisfies the stated criteria for assessment or they may simply be presented as they were submitted for assessment by the former student. ${ }^{5}$

\footnotetext{
${ }^{2}$ D Royce Sadler, "Interpretations of Criteria-based Assessment and Grading in Higher Education," Assessment and Evaluation in Higher Education 30, no.2 (2005): 175 - 198, 192.

${ }^{3}$ Margaret Price, Karen Handley, and Jill Millar, "Feedback: focusing attention on engagement" Studies in Higher Education, 36 no.8 (2011): 879-896.

${ }^{4}$ Jenny Scoles, Mark Huxham \& Jan McArthur (2012), " No longer exempt from good practice: using exemplars to close the feedback gap for exams" Assessment and Evaluation in Higher Education, 2 DOI:10.1080/02602938.2012.674485

${ }^{5}$ The following examples of exemplars may help in the understanding of the concept:
} 
It is therefore stated that exemplars should be thought of in the broadest possible context and are representative of examples of indicative standards of work as previously completed by students or produced by educators.

\section{The Case for Using Exemplars}

Established literature suggests a number of concurrent reasons for the use of exemplars in an educational setting. Key reasons for use include that feedback on marked assessment items is provide too late to be of educational benefit for students, student's desire exemplars, exemplars leading to the improvement of understanding of key concepts and the improvement of a student's grade and the development of consistent application of criteria and standards. These issues are examined in more detail below.

\subsection{Feedback on Marked Assessment Is Provided Too Late To Be Of Benefit}

Feedback on assessment performance is critical to the growth of a student's understanding of core principles, skills and academic knowledge of subject content. ${ }^{6}$ It is a major tool that educators have used for considerable periods of time. It is from formative feedback that students gain an understanding of where their strengths and weaknesses lie in relation to any particular topic. But it has been argued that when feedback is provided days or even weeks after a student has submitted an item of work for assessment, that this is simply too late to be of benefit to the student. ${ }^{7}$ This is one of the key concerns of Carless, who discusses in detail the concern with feedback students receive primarily because it is received too late to be of perceived benefit to them. ${ }^{8}$ Carless is not alone in his observations of the value of feedback being received too late, similar comments have also been made by Higgins, Harley and Skelton ${ }^{9}$. That is, students receive feedback at too late a stage in a course to be of use to improve their marks in future items of assessment and of course that feedback cannot change the grade they were awarded for that item of assessment.

http://www.boardofstudies.nsw.edu.au/hsc exams/hsc2011exams/, http://www.ukessays.com/essays/english/wuthering-heights.php, http://www.edu.gov.on.ca/eng/curriculum/elementary/writing18ex.pdf

${ }^{6}$ David Nicol, Avril Thomson and Caroline Breslin, "Rethinking feedback practices in higher education: a peer review perspective" Assessment and Evaluation in Higher Education 38. no.6 (2013): 1-20. Iris Vardi, "Effectively feeding forward from one written assessment task to the next" Assessment \& Evaluation in Higher Education 38 (5) 2013. 599-610. Alasdair Blair and Samantha McGinty, " Feedback-dialogues: exploring the student perspective" Assessment and Evaluation in Higher Education 38 (4) 2013. 466-476.

7 MacLellan, E. 2001. “Assessment for Learning: The Differing Perceptions of Tutors and Students. "Assessment \& Evaluation in Higher Education 26 (4): 307-318.

${ }^{8}$ David Carless, "Differing Perceptions in the Feedback Process," Studies in Higher Education 31, no.2 (2006): 219-233, 227.

${ }_{9}$ Richard Higgins, Peter Hartley and Alan Skelton, "Getting the message across: the problem of communicating assessment feedback" Teaching in Higher Education 6, no.2 (2001): 269-274
Exemplars may be of practical benefit to students in assisting them to complete forthcoming items of assessment. This view is supported by both Hounsell ${ }^{10}$ and Handley and Williams ${ }^{11}$, who both indicate that the poor timing of feedback constitutes solid grounds for the educator to seriously consider the use of exemplars to assist students to identify weaknesses immediately rather than after the completion of an item of assessment when it is too late to do anything about it to improve their grade. Exemplars which are provided to students well before any item of assessment is due would help to overcome the notice of delayed feedback being ineffectual.

\subsection{Students Show a Desire for Exemplars}

There appears to be a significant body of evidence suggesting an overwhelming desire from students that they be provided with exemplars.

In 2009 Newlyn and Juriansz ${ }^{12}$, basing their research project on one conducted by O'Donovan, Price and Rust ${ }^{13}$, reported on the results of a survey they undertook of the attitudes to the provision of exemplars from a group of over 250 students of a first year contract law course conducted at an Australian university. In the context of a perceived misunderstanding of exemplars and their potential value by students, they reported that there was strong support for the use of exemplars from the students.

Wimshurst and Manning, ${ }^{14}$ basing their research project on those previously undertaken by Sadler ${ }^{15}$ surveyed students after providing them with exemplars before they completed an item of assessment. They reported that every respondent to the survey commented in a positive fashion on the value of the exemplars and state that comments ranged from "stating that they had developed a better sense of coherence and integration in complex pieces through to

\footnotetext{
${ }^{10}$ Dai Hounsell, 'Towards more sustainable feedback to students.' In: David Boud and Nancy Falchikov, (eds). Rethinking Assessment in Higher Education. Learning for the Longer Term (Routledge: London, 2007) 101-113.

${ }^{11}$ Karen Handley and Lindsay Williams, "From Copying to Learning: Using Exemplars to Engage Students with Assessment Criteria and Feedback" Assessment and Evaluation in Higher Education 36, no.1 (2011): 95-108.

${ }_{12}$ Newlyn D, Juriansz J, 2009, Improving Performance in Contractual Problem Solving, Clarifying Criteria and Standards through the use of Exemplars, Journal of the Australasian Law Teachers Association, vol 2, no. 1 \& 2, 185-196.

${ }^{13}$ Berry O'Donovan, Margaret Price and Chris Rust, 'Improving Students' Learning by Developing their Understanding of Assessment Criteria and Processes' (2003) 28(2) Assessment and Evaluation in Higher Education $147-164$.

${ }^{14}$ Kerry Wimshurst and Matthew Manning, " Feed-forward assessment, exemplars and peer marking: evidence of efficacy" Assessment and Evaluation in Higher Education 38, no.4 (2013) 451-465.

${ }^{15}$ Sadler, D.R. 2010. Beyond feedback: Developing student capability in complex appraisal.

Assessment \& Evaluation in Higher Education 35, no. 5: 535-550.
} 
feeling more engage with the course..."16

Undertaking an empirical study of the value of exemplars presented in an online environment, Handley and William ${ }^{17}$ indicated that there was an overwhelming positive response from students to the provision of exemplars. They state that $73 \%$ of surveyed students rated the provision of an exemplar as 'very useful'.

Scoles, Huxham and McArthur, ${ }^{18}$ indicate students, that they surveyed after the introduction of exemplars designed to assist students with their exam preparation, showed overwhelming support for the use of exemplars. They state that the exemplars "helped them (students) understand what was wanted from their lecturers" ${ }^{19}$ and was perhaps best illustrated via the following comment (which includes features of speech) they received "it's quite nice to use it in conjunction with conversations with lecturers as well because something you didn't know before you can also clarify with a lecturer; if you are unclear why a certain person got a grade um for a particular answer and you can't see it any differently to another answer that got a lower grade." 20

\subsection{Proving Exemplars Can Lead To an Improvement in Students Marks}

Arguably any claim that the provision of exemplars leads to an improvement in students marks will be difficult to substantiate as assessment occurs within a complex web of contextual and relational factors rather than in a vacuum. Handley and Williams discuss this by indicating that it may be almost impossible to demonstrate conclusively that the provision of an exemplar was the actual or sole cause of an increase in marks for any given student, given that numerous other factors such as motivation and environmental changes could equally have been claimed to have been responsible for any recorded change. ${ }^{21}$ However there have been a number of research projects, some longitudinal in nature, which have claimed that the provision of exemplars does

\footnotetext{
${ }^{16}$ Kerry Wimshurst and Matthew Manning, " Feed-forward assessment, exemplars and peer marking: evidence of efficacy" Assessment and Evaluation in Higher Education 38, no.4 (2013) 451-465. 40.

${ }^{17}$ Handley, K., and L. Williams. 2011. From copying to learning: Using exemplars to engage students with assessment criteria and feedback. Assessment \& Evaluation in Higher Education 36, no. 1: 95-108. ${ }^{18}$ Jenny Scoles, Mark Huxham \& Jan McArthur (2012), " No longer exempt from good practice: using exemplars to close the feedback gap for exams" Assessment and Evaluation in Higher Education, DOI:10.1080/02602938.2012.674485

19 Jenny Scoles, Mark Huxham \& Jan McArthur (2012), " No longer exempt from good practice: using exemplars to close the feedback gap for exams" Assessment and Evaluation in Higher Education, 6 DOI:10.1080/02602938.2012.674485

20 Jenny Scoles, Mark Huxham \& Jan McArthur (2012), " No longer exempt from good practice: using exemplars to close the feedback gap for exams" Assessment and Evaluation in Higher Education, 7 DOI:10.1080/02602938.2012.674485

${ }^{21}$ Karen Handley and Lindsay Williams, 'From Copying to Learning: Using Exemplars to Engage Students with Assessment Criteria and Feedback' (2009) Assessment and Evaluation in Higher Education 1.7
}

lead to an increase in students marks.

In a research project conducted by O'Donovan, Price and Rust $^{22}$, students were invited to take part in voluntary workshops where they were presented with exemplars relevant to their forthcoming assessment. They were given published criteria and standards and asked to grade two exemplars. Those exemplars were from previous students who had completed the same course. The provided exemplars were designed to be indicative of very different levels of achievement. The authors report that those students who took part in the voluntary workshops experienced significant increases in their grades after this experience as compared to those students who did not avail themselves of the opportunity.

Huxham reports on a longitudinal study he conducted with hundreds of biology students at a United Kingdom university. Huxham compared students' preference for two different types of feedback (personalised comments and exemplars). Huxham indicates that although a majority of students preferred feedback be provided by personalised comments, the most significant improvement to students marks was produced via the provision of exemplars.

In 2012, Scoles, Huxham and McArthur ${ }^{23}$ using a mixed-methods approach of qualitative and quantitative analysis reported on a project they had undertaken to measure the effectiveness of using three annotated exemplars (average $50-60 \%$, good $60-70 \%$ and excellent $70 \%+$ ) to improve the exam performance of their students at a Scottish University. Undertaking a statistical analysis between those students who accessed the available exemplars (available online) and those students who did not access them showed a highly significant difference in the mean marks students achieved in the final exam.

Newlyn and Spencer ${ }^{24}$, in perhaps the study with the largest reported number of participants, discuss the results they obtained when they provided exemplars to students undertaking an introductory law unit at an Australian university. In their study, the researchers presented exemplars to over 2500 students in an attempt to improve the students' final exam performance. They described how, for an extended period of time, the introductory law unit had been characterised by relatively good interim assessment performance but very poor exam performance. In an attempt to address this problem a series of exam exemplars representing the full range of grades available was presented to students during the teaching semester. These exemplars

\footnotetext{
22 Berry O'Donovan, Margaret Price and Chris Rust, 'Improving Students' Learning by Developing Their Understanding of Assessment Criteria and Processes' (2003) 28(2) Assessment and Evaluation in Higher Education 147.

23 Jenny Scoles, Mark Huxham \& Jan McArthur (2012), " No longer exempt from good practice: using exemplars to close the feedback gap for exams" Assessment and Evaluation in Higher Education, DOI: $10.1080 / 02602938.2012 .674485$

${ }^{24}$ Newlyn D, Spencer L, 2010, Improving Student Performance in Interdisciplinary Law Unit Assessment by Providing Annotated Exemplars, Journal of the Australasian Law Teachers Association, vol 3, no. $1 \& 2,67-75$.
} 
were taken from students of previous semesters who had completed similar examination tasks. They were annotated by the teaching staff to reflect the published criteria and standards. The researchers categorically state that the provision of exemplars led to an increase in students marks. In particular there was a large increase in students achieving at the highest grade levels available.

In 2013 Wimshurst and Manning ${ }^{25}$, undertook a research project involving students enrolled in a criminology course at an Australian university in order to determine whether the use of exemplars correlated in any way to changes in students grades. The project involved the researchers intervening (as they called it) by providing 97 students with six exemplars of different grade levels from previous students, with the aim of improving the quality of responses in written work from current students and thus leading to an improvement in the awarding of future grades. The researchers attempted to take into account various factors such as gender, age, mode of study (on campus or distance based) and grade point average (GPA) in their determinations of the benefit of the provision of exemplars. They conclude that not only did the provision exemplars improve students overall grades for the unit they also enhanced student engagement with the subject.

\subsection{Providing Exemplars Ensures Transparent Communication of Criteria and Standards}

Academic integrity of the grades awarded to students requires the consistent and transparent communication of criteria and standards to students. Criteria and standards assessment is becoming increasingly common in different educational environments. As Sadler states, criteria is a property or characteristic by which the quality of something may be judged, specifying criteria nominates qualities of interest and utility but does not have anything to offer, or make any assumptions about, actual quality whilst a standard is a definite level of achievement aspired to or attained. That is standards are about definite levels of quality or achievement, or performance. ${ }^{26}$

Criteria and standards are used for a variety of reasons, including potentially being required by institution wide or faculty specific policy or because of the belief that they provide for consistency and reliability in the assessment of students work. That is, any student would be entitled to know of the required criteria and standard of the work expected of them before submitting an assessment task and then to be assessed specifically against that stated criteria and standard. ${ }^{27}$ But students may not necessarily appreciate how

\footnotetext{
${ }^{25}$ Kerry Wimshurst and Matthew Manning, "Feed-forward assessment, exemplars and peer marking: evidence of efficacy" Assessment and Evaluation in Higher Education 38, no.4 (2013) 451-465.

${ }^{26}$ Sadler, D. R. (1987) Specifying and promulgating achievement standards, Oxford Review of Education, 13(2), 191-209. 194.

${ }^{27}$ Effie Maclellan, 'Authenticity in Assessment Tasks: A Heuristic Exploration of Academics' Perceptions' (2004) 23(1) Higher Education Research and Development 19.
}

exemplars can be taken to represent or map specific criteria and standards.

Sadler notes that it is important that students be educated about the value of exemplars in communicating standards and criteria. ${ }^{28}$ Similarly, Orsmond, Merry and Reiling make it clear that exemplars can greatly assist students to appreciate standards and criteria but they need to me made aware of this benefit. ${ }^{29}$ Exemplars make the criteria and standards concrete and tangible as they actually show what is requires in context, rather than simply listing elements that must be achieved by a student in order to achieve a particular grade level. ${ }^{30}$ This is exemplified by Sadler who states "[V]erbal descriptions are always to some degree vague or fuzz...A fuzzy standard cannot, therefore, be defined into existence." ${ }^{31}$

Simply providing criteria and standards to students, no matter how well explained, detailed or elaborated they may be, is insufficient. Providing those criteria and standards in context through the provision of an exemplar is much more effective in communicating those criteria and standards to students. ${ }^{32}$ Biggs exemplifies this in his statement that "[i]n criterion-referenced assessment, students see the situation as a designated learning experience; to get a high grade they have to know the goals and learn how to get there, with a premium on attributions involving effort, study skill and knowing the right procedures." ${ }^{33}$ Providing them with exemplars engages them in this process.

\section{The Case against Using Exemplars}

It is not the intention of this paper to suggest that exemplars are perfect nor that they can solve every problem that the educator has nor that they are the only possible way to improve a students' level of understanding and/or results. It is not suggested that exemplars can replace the necessary teaching of the required or mandated course content or skills nor that exemplars be used as a replacement for genuine engagement with students. A number of reasons have already been set out in this paper as to the case for the use of exemplars to assist students and it is appropriate in order to provide a balanced view of the topic that consideration be give to espoused reasons against the use of exemplars.

\footnotetext{
${ }^{28}$ D Royce Sadler, 'Formative Assessment: Revisiting the Territory' (1998) 5(1) Assessment in Education 77 - 84.

${ }^{29}$ Paul Orsmond, Stephen Merry and Kevin Reiling, 'The Use of Exemplars and Formative Feedback when Using Student Derived Marking Criteria in Peer and Self-Assessment' (2002) 27(4) Assessment \& Evaluation in Higher Education 309

${ }^{30}$ Catherine Taylor, 'Assessment for Measurement or Standards: The Peril and Promise of Large-scale Assessment Reform' (1994) 31(2) American Educational Research Journal 231, 243.

${ }^{31}$ D Royce Sadler, 'Specifying and promulgating achievement standards' (1987) 13(2) Oxford Review of Education 191, 202, 204.

${ }^{32}$ Kathryn Ecclestone, "I know a 2: I when I see it": understanding criteria for degree classification in franchised university programs' (2001) 25 Journal of Further and Higher Education 301.

33 John Biggs, Teaching for Quality Learning at University $\left(2^{\text {nd }}\right.$ ed, 2003) 59.
} 
Ostensibly these reasons revolve around the issues of exemplars being resource inefficient due to the large amount of time associated with their development and potentially leading to plagiarism issues and/or a curtailing of student creativity. These issues are examined below in more detail.

\subsection{Issues of Time and Consent}

Issues of time and consent are very important considerations in the argument against the potential use of exemplars. The construction of exemplars takes a large amount of time. This amount of time should not be underestimated. Initially a decision as to whether or not to use exemplars needs to be made. Then someone needs to be assigned to collect or construct the exemplars. If the exemplars are to take the form of model answers constructed by the teaching staff this may take a smaller amount of time as compared to exemplars which are to be constituted by previous students work. But nonetheless it will still take a large amount of time for that teacher to identify which topics should form the focus of the model answers and to construct the model answer with reference to the establish criteria and standards.

In the instance of exemplars which are to be made from previous students work, issues of time become more important. Newlyn and Spencer ${ }^{34}$ note that a considerable amount of time will be taken to gain the permission of those who have undertaken the previous items of assessment. Permission may not be readily granted by former students and there may be a formal process at each institution with respect to ethical clearances to use students work in these situations. A decision needs to be made in this situation as to how many exemplars should be obtained. Only one? One good and one bad? Or one from each potential grade that could be awarded? The larger the number of exemplars to be used the larger the amount of time that will be taken in their selection.

Further time will be taken in assessing which of the available examples you may wish to use on the basis of how well they may or may not address the stated criteria for assessment of their work. Transcription of the assessment items into a typed format may be necessary, particularly when the assessment item had been hand written such as in an exam situation. ${ }^{35}$ Then the educator may wish to annotate the provided examples so that they directly and specifically state why a particular mark was awarded and exactly where and how or why each relevant criteria was addressed. The more detailed these annotations the more time that the process will take.

The more time taken the more detailed and useful the

\footnotetext{
${ }^{34}$ Newlyn D, Spencer L, 2009, Using Exemplars in an Interdisciplinary Law Unit: Listening to the student's voices, Journal of the Australasian Law Teachers Association, vol 2, no. 1 \& 2, 121-133.

35 Jenny Scoles, Mark Huxham \& Jan McArthur (2012), " No longer exempt from good practice: using exemplars to close the feedback gap for exams" Assessment and Evaluation in Higher Education, 3 DOI:10.1080/02602938.2012.674485
}

exemplar produced is likely to be. Consideration should be given to making the exemplar as generic as possible, of course without compromising the integrity or usefulness of the process, as this could ensure that the exemplar could be used with varied cohorts at multiple institutions for years ahead. The entire process is likely to take a matter of months before it can be finalised.

\subsection{Providing Exemplars Suppresses Creativity and Leads To Plagiarism}

A genuine concern that educators may have is the idea that providing exemplars 'gives students the answer' or that it leads to plagiarism, 'parroting' or copying. Another concern is that students may consider that the provided exemplar provides the 'only' way to answer a particular question or the 'best' way to do so. Indeed there is a body of established literature that has examined all of these particular concerns. ${ }^{36}$

The problem of students copying or plagiarising the provided exemplars is a real one. ${ }^{37}$ There may be some students, even though educated about the concept of plagiarism, who are either oblivious or too tempted to ignore a provided exemplar and want to copy it directly. To a large extent this problem could be avoided if considered during the construction phase. For example, in situations where a particular skill is being demonstrated the exemplar provided should not be directly related to the current course content. Consider the situation where an educator wished to teach the skill of essay writing in an English literature course. If that course examined the writings of Bronte or Austin, then the provided exemplar could be from Dickens or Conrad. The creator of the exemplar would still need to ensure that the criteria and standards and skills to be demonstrated were still present in the exemplar that they intended to use, but by using a different author the ability of the student to directly copy from the exemplar is removed, but the skill of essay writing would still be contextually demonstrated.

Alternatively, when using examples from previous versions of the same course which examine the same content, the constructor of the exemplar would need to ensure that the content provided in the exemplar was not linked to the content being examined in the current semester, although the exemplar may well demonstrate how the same or substantially similar criteria and standards were applied. Collectively, these measures would reduce the possibility of plagiarism raised in the literature.

\section{Conclusions}

The use of exemplars in an educational setting is not new.

\footnotetext{
${ }^{36}$ Carol Parker, 'Writing Through the Curriculum: Why Law Schools Need It, and How to Achieve It' (1997) 76 Nebraska Law Review 561.

37 Patricia G Montana, 'Meeting Students' Demand for Models of Good Legal Writing' (2010, March) (Paper No 10-0183) St John's University School of Law Legal Studies Research Paper Series 1-2, $<$ http://ssrn.com/abstract=1569551> on 19 February 2013.
} 
What may be new is the idea of thinking about the use of exemplars in a rigorous scholarly fashion. That is, thinking about the relevant issues such as the inherent educational value of using exemplars to improve student's performance but yet being concerned about the potential stifling of creativity by using exemplars.

The provision of exemplars in an education setting should not be seen as a single solution to the issue of quality assessment. Instead exemplars should be seen as a piece of the entire package of tools needed to assist students. Exemplars can provide information, skills, content and messages in a way that no other teaching methodology can. Exemplars are a very useful way in which students can be helped to gain a firm understanding, in a concrete, contextual, and non-threatening fashion, of exactly what it is that is required of them in order to succeed to their desired level of achievement within a particular unit or in any particular assessment task.

The choice of whether or not to engage with the use of exemplars in any individual area of study should be one which rests with the educators responsible for the teaching of that area. It should not be one which is imposed on any person without a rigorous and genuine discussion of the merits of using an exemplar. Proper thought need to be provided with regards to the issues raised in this paper before that decision is made. An exemplar which is constructed in haste and without proper thought of the issues raised in this paper is likely to be ineffectual.

\section{REFERENCES}

[1] Margaret Price, Karen Handley, Jill Miller and Berry O'Donovan, "Feedback: all that effort, but what is the effect?" Assessment and Evaluation in Higher Education, 35 no. 3 (2011): 277-289.

[2] D Royce Sadler, "Interpretations of Criteria-based Assessment and Grading in Higher Education," Assessment and Evaluation in Higher Education 30, no.2 (2005): 175 198, 192.

[3] Margaret Price, Karen Handley, and Jill Millar, "Feedback: focusing attention on engagement" Studies in Higher Education, 36 no.8 (2011): 879-896.

[4] Jenny Scoles, Mark Huxham \& Jan McArthur (2012), " No longer exempt from good practice: using exemplars to close the feedback gap for exams" Assessment and Evaluation in Higher Education, 2 DOI:10.1080/02602938.2012.674485

[5] The following examples of exemplars may help in the understanding of the concept:

http://www.boardofstudies.nsw.edu.au/hsc_exams/hsc2011e xams/,

http://www.ukessays.com/essays/english/wuthering-heights. php,

http://www.edu.gov.on.ca/eng/curriculum/elementary/writin g18ex.pdf

[6] David Nicol, Avril Thomson and Caroline Breslin, "Rethinking feedback practices in higher education: a peer review perspective" Assessment and Evaluation in Higher Education 38. no.6 (2013): 1-20. Iris Vardi, "Effectively feeding forward from one written assessment task to the next" Assessment \& Evaluation in Higher Education 38 (5) 2013. 599-610. Alasdair Blair and Samantha McGinty, " Feedback-dialogues: exploring the student perspective" Assessment and Evaluation in Higher Education 38 (4) 2013. 466-476.

[7] MacLellan, E. 2001. "Assessment for Learning: The Differing Perceptions of Tutors and Students. "Assessment \& Evaluation in Higher Education 26 (4): 307-318.

[8] David Carless, "Differing Perceptions in the Feedback Process," Studies in Higher Education 31, no.2 (2006): 219-233, 227.

[9] Richard Higgins, Peter Hartley and Alan Skelton, "Getting the message across: the problem of communicating assessment feedback" Teaching in Higher Education 6, no.2 (2001): 269-274

[10] Dai Hounsell, 'Towards more sustainable feedback to students.' In: David Boud and Nancy Falchikov, (eds). Rethinking Assessment in Higher Education. Learning for the Longer Term (Routledge: London, 2007) 101-113.

[11] Karen Handley and Lindsay Williams, "From Copying to Learning: Using Exemplars to Engage Students with Assessment Criteria and Feedback" Assessment and Evaluation in Higher Education 36, no.1 (2011): 95-108.

[12] Newlyn D, Juriansz J, 2009, Improving Performance in Contractual Problem Solving, Clarifying Criteria and Standards through the use of Exemplars, Journal of the Australasian Law Teachers Association, vol 2, no. 1 \& 2, 185-196.

[13] Berry O'Donovan, Margaret Price and Chris Rust, 'Improving Students' Learning by Developing their Understanding of Assessment Criteria and Processes' (2003) 28(2) Assessment and Evaluation in Higher Education 147 164.

[14] Kerry Wimshurst and Matthew Manning, " Feed-forward assessment, exemplars and peer marking: evidence of efficacy" Assessment and Evaluation in Higher Education 38, no.4 (2013) 451-465.

[15] Sadler, D.R. 2010. Beyond feedback: Developing student capability in complex appraisal. Assessment \& Evaluation in Higher Education 35, no. 5: 535-550.

[16] Kerry Wimshurst and Matthew Manning, " Feed-forward assessment, exemplars and peer marking: evidence of efficacy" Assessment and Evaluation in Higher Education 38, no.4 (2013) 451-465. 40.

[17] Handley, K., and L. Williams. 2011. From copying to learning: Using exemplars to engage students with assessment criteria and feedback. Assessment \& Evaluation in Higher Education 36, no. 1: 95-108.

[18] Jenny Scoles, Mark Huxham \& Jan McArthur (2012), " No longer exempt from good practice: using exemplars to close the feedback gap for exams" Assessment and Evaluation in Higher Education, DOI:10.1080/02602938.2012.674485

[19] Jenny Scoles, Mark Huxham \& Jan McArthur (2012), " No longer exempt from good practice: using exemplars to close the feedback gap for exams" Assessment and Evaluation in 
Higher Education, 6 DOI:10.1080/02602938.2012.674485

[20] Jenny Scoles, Mark Huxham \& Jan McArthur (2012), " No longer exempt from good practice: using exemplars to close the feedback gap for exams" Assessment and Evaluation in Higher Education, 7 DOI:10.1080/02602938.2012.674485

[21] Karen Handley and Lindsay Williams, 'From Copying to Learning: Using Exemplars to Engage Students with Assessment Criteria and Feedback' (2009) Assessment and Evaluation in Higher Education 1.7

[22] Berry O'Donovan, Margaret Price and Chris Rust, 'Improving Students' Learning by Developing Their Understanding of Assessment Criteria and Processes' (2003) 28(2) Assessment and Evaluation in Higher Education 147.

[23] Jenny Scoles, Mark Huxham \& Jan McArthur (2012), " No longer exempt from good practice: using exemplars to close the feedback gap for exams" Assessment and Evaluation in Higher Education, DOI:10.1080/02602938.2012.674485

[24] Newlyn D, Spencer L, 2010, Improving Student Performance in Interdisciplinary Law Unit Assessment by Providing Annotated Exemplars, Journal of the Australasian Law Teachers Association, vol 3, no. 1 \& 2, 67-75.

[25] Kerry Wimshurst and Matthew Manning, "Feed-forward assessment, exemplars and peer marking: evidence of efficacy" Assessment and Evaluation in Higher Education 38, no.4 (2013) 451-465.

[26] Sadler, D. R. (1987) Specifying and promulgating achievement standards, Oxford Review of Education, 13(2), 191-209. 194.

[27] Effie Maclellan, 'Authenticity in Assessment Tasks: A Heuristic Exploration of Academics' Perceptions' (2004) 23(1) Higher Education Research and Development 19.

[28] D Royce Sadler, 'Formative Assessment: Revisiting the Territory' (1998) 5(1) Assessment in Education 77 - 84.
[29] Paul Orsmond, Stephen Merry and Kevin Reiling, 'The Use of Exemplars and Formative Feedback when Using Student Derived Marking Criteria in Peer and Self-Assessment' (2002) 27(4) Assessment \& Evaluation in Higher Education 309

[30] Catherine Taylor, 'Assessment for Measurement or Standards: The Peril and Promise of Large-scale Assessment Reform' (1994) 31(2) American Educational Research Journal 231, 243

[31] D Royce Sadler, 'Specifying and promulgating achievement standards' (1987) 13(2) Oxford Review of Education 191, $202,204$.

[32] Kathryn Ecclestone, "I know a 2: I when I see it": understanding criteria for degree classification in franchised university programs' (2001) 25 Journal of Further and Higher Education 301.

[33] John Biggs, Teaching for Quality Learning at University (2nd ed, 2003) 59.

[34] Newlyn D, Spencer L, 2009, Using Exemplars in an Interdisciplinary Law Unit: Listening to the student's voices, Journal of the Australasian Law Teachers Association, vol 2, no. $1 \& 2,121-133$.

[35] Jenny Scoles, Mark Huxham \& Jan McArthur (2012), " No longer exempt from good practice: using exemplars to close the feedback gap for exams" Assessment and Evaluation in Higher Education, 3 DOI:10.1080/02602938.2012.674485

[36] Carol Parker, 'Writing Through the Curriculum: Why Law Schools Need It, and How to Achieve It' (1997) 76 Nebraska Law Review 561.

[37] Patricia G Montana, 'Meeting Students' Demand for Models of Good Legal Writing' (2010, March) (Paper No 10-0183) St John's University School of Law Legal Studies Research Paper Series 1-2, <http://ssrn.com/abstract $=1569551>$ on 19 February 2013 